\title{
An Upper Ontology for Benefits Management of Cloud Computing
}

\author{
Richard Greenwell*, Xiaodong Liu and Kevin Chalmers \\ Institute for Informatics and Digital Innovation, \\ Edinburgh Napier University, Edinburgh, UK
}

\begin{abstract}
Benefits Management provides an established approach for decision making and value extraction for IT/IS investments and, can be used to examine cloud computing investments. The motivation for developing an upper ontology for Benefits Management is that the current Benefits Management approaches do not provide a framework for capturing and representing semantic information. There is also a need to capture benefits for cloud computing developments to provide existing and future users of cloud computing with better investment information for decision making. This paper describes the development of an upper ontology to capture greater levels of knowledge from stakeholders and IS professionals in cloud computing procurement and implementation. Complex relationships are established between cloud computing enablers, enabling changes, business changes, benefits and investment objectives
\end{abstract}

Keywords-Ontology Generation; Benefits Management; Cloud Computing

\section{INTRODUCTION}

The Benefits Management approach has been developed over a number of years by researchers such as Ward and Daniel [1] and Peppard et al.[2]. The approach allows stakeholders to gain maximum business benefit from IS/IT investments by considering the linkage between investments and the business benefits they generate. Ward and Daniel's work [1] shows high levels of dissatisfaction with the benefits derived from IS/IT activities, with $81 \%$ of those surveyed having dissatisfaction with the evaluation and review of benefits and $75 \%$ having dissatisfaction with the planning and delivery of benefits respectively.

Cloud computing is a relatively new IS/IT technology that many organisations are beginning to use and are considering investing in. Organisations may not have considered how such investments will deliver business benefits. This paper examines Benefits Management in cloud computing, by using a number of primary and secondary case studies, to provide a unique contribution in this area. The Benefits Management approach is used to develop an ontology to structure the knowledge gained from the case studies.

The motivation for using an ontology is to abstract knowledge and reasoning from the ontology in order to develop a number of reasoning approaches based on attributes such as organisation size, type of cloud technology used and other factors to provide clear, precise and unambiguous definitions of the benefits derived from cloud computing. Future work will see the expansion of the ontology to allow multiple stakeholders to add further case studies. This will provide additional reasoning and scenarios to the ontology.

The main contributions of this paper are to advance the Benefits Management technique through the introduction of semantics and to develop an ontology from a number of case studies which can be accessed and edited by other researchers. The ontology developed for Benefits Management will allow a service to be created, which can be accessed and enhanced by multiple stakeholders.

This paper will now continue with a discussion of the Benefits Management approach. The application to cloud computing will then be presented as a number of enablers. The process of the generation of an upper ontology will then be described. A number of case studies are shown encoded into the ontology. The resulting ontology structure and conclusions will be described along with further work.

\section{BENEFITS MANAGEMENT}

The Benefits Management approach was developed out of a dissatisfaction with IS/IT projects' failure to deliver business value. Benefits Management is defined by Ward and Daniel [1] as "The process of organizing and managing such that potential benefits arising from the use of IS/IT are actually realized". The approach concentrates on benefits delivery, obtaining value from investments and involving stakeholders. There is emphasis on change management, that is, the importance of IS/IT investments only delivering benefits through organisational change.

Ward and Daniel [1] describe the need for a common language and reference model in exploring benefits enabled by IS/IT investments. Using an ontology driven approach, multiple stakeholders can develop vocabularies, terms and semantics and map them to form a common discourse. The authors also describe the importance of context, while the semantic modelling and mapping tools help contributors to model context in the Benefits Management process.

The Benefits Management approach attempts to link IS/IT enablers such as new technology advances to create change in the organisation. The changes are termed enabling changes. IS/IT enablers are only useful if they enable change in the organisation. Enabling changes trigger business changes in the organisation that delivers benefits. The benefits meet clearly defined investment objectives. The Benefits Management process is encapsulated in the Benefits Dependency Network (BDN) shown in the figure below. 


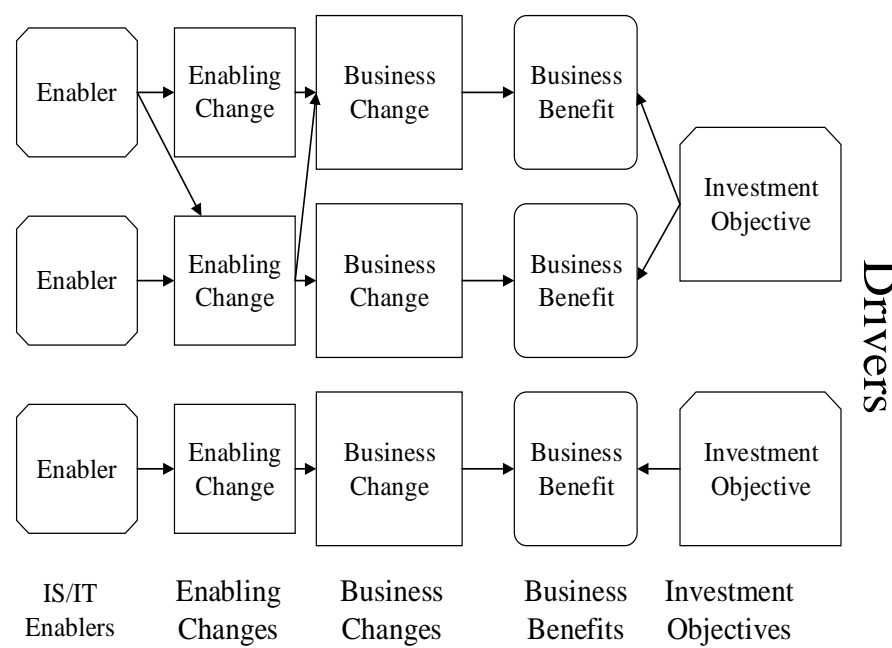

Fig. 1. Benefits Dependency Network

A holistic approach should be taken in the Benefits Management approach. Intangible benefits should not be ignored. Previous approaches to examining the value delivered from IS/IT investment have concentrated on financial measures and may have ignored the full spectrum of benefits.

The classification of benefits is the next stage of the approach. A business case is presented to key stakeholders who will then make investment decisions. The more explicitly a benefit can be expressed the easier it is to gain commitment to investment. A benefit expressed in financial terms will more easily gain acceptance than a benefit that is merely observable. Benefits can also be classified in terms of the next action for a given benefit, if something new should be done, continued or stopped.

The final stage of the Benefits Management process is to identify benefits into the types. High potential investments may deliver high value but carry high risk. Strategic investments are central to the success of the business. Key operational investments can be improved to increase productivity in the business. Support investments deliver the least value to the business and may be stopped if they become more expensive.

An issue with the current Benefits Management process is that it does not express the elements of the process (such as enablers, changes and benefits) and the relationships between the elements of the process in terms of semantics. A key contribution of this paper is to use an ontology to improve the knowledge representation within the Benefits Management process. New ontology tools such as Web Protégé [3] allow multiple stakeholders to build a Benefits Management ontology through collaborative developments.

In the next section IS/IT enablers seen in cloud computing will be considered.

\section{Cloud COMPUTING ENABLERS}

A number of IS/IT enabling technologies have been identified in cloud computing. Provision models such Infrastructure as a Service (IaaS), Platform as a Service (PaaS) and Software as a Service (SaaS) have been defined by NIST
[4]. IaaS is the lowest level of enabler, where users procure hardware and operating system resources at a cost. PaaS brings together infrastructure, programming languages and data storage in a single package. SaaS provides customers with the ability to rent software packages on demand. Ownership models of cloud resources have also been defined by NIST [4] as public clouds, private clouds and hybrid clouds. Public clouds are provided by third parties at an agreed service level and price. Private clouds use cloud technology to provide services to customers within an organisation. Hybrid clouds use both public and private clouds to provide services to customers.

Technologies built on cloud computing such as Big Data [5], Data Science [6] and storage services [7] are key enablers for generating change and benefits in cloud computing investments.

A number of enablers have been identified from primary and secondary sources [8][9][10][11][12][13][14] which are now discussed. Cost is a primary enabler, IaaS provides low cost of ownership and the ability to manage cost. Ease of movement from test to production is facilitated by allowing a number of virtual instances can be procured and used to move from test to production. Large scale storage with low cost of ownership is provided by storage that can be purchased on demand and is managed and backed-up in the cloud.

Alternative ways of working and new products are being created by cloud computing. Shared development spaces between organisations especially in public clouds, can provide joint developments or provide greater customer intimacy. Organisations can create new products, especially on the PaaS platform. Data Science, Big Data and 'Smart Cities' [15] become feasible for small and medium size organisations. Flexibility of resources allow organisations can downsize/upsize on demand.

New markets and marketing can be accessed. The marketing power of cloud computing allow cloud solutions to be marketing tools, with an organisation's status improved by having a cloud computing solution. Many large corporations and government organisations require solutions to be cloud based, for example the United Kingdom's G-Cloud [16].

Private and public organisations can offer infrastructure and services to other organisations, to reduce ownership cost or to generate revenue. Public organisations can create cloud infrastructure for economic development [17].

There are a number of operational enablers in cloud computing adoption. Cloud storage and infrastructure solutions can be used to manage disaster recovery [18]. Infrastructure management tasks can be reduced, which allows employees to concentrate on more skilled work or to develop new skills. Cloud services can be delivered to a number of devices [19]. The security of the infrastructure can be improved [20].

\section{Collaborative Ontology CREATION}

This section examines how ontologies are created, in particular upper ontologies that concentrate on a specific subject area, such as Benefits Management. Ontologies allow 
the capture and formalisation of knowledge using semantics. Knowledge is represented as terminology (via description logics) and assertions represented in the terminology. This provides the ability to capture greater knowledge in the Benefits Management process. The ontology can be queried by languages such as SPARQL [21].

Benefits Management brings together a number of stakeholders in an organisation to consider how IS/IT enablers (such as cloud computing) can generate benefits. Research into ontologies and associated description logics has concentrated on biomedical research [22] and the novel application to new areas such as Benefits Management can be seen to deliver great value to organisations.

Upper ontology are designed for narrowly defined subject areas. A number of upper ontologies have been developed, for example the Good Relations ontology [23] in commerce and NASA QUDT [24] for units of measurement. In any development of Benefits Management ontology there will be a collaborative effort to define ontology structure and content.

Walk et al. [25] discuss collaborative ontology engineering projects. The collaborative approach is ideally suited to creating explicit specifications and shared conceptualisations of benefits derived from IS/IT investments from multiple stakeholders. Stakeholders can collaborate using tools such as WebProtégé [3] to work on the structure of the ontology (the terminology or T-BOX and the relational aspects of ontology or R-BOX) and the individual instances of the ontology (the assertions or A-BOX). Such tools allow auditing, change history and correctness of the ontology to be maintained. The process of ontology generation is more difficult than off the shelf collaborative tools that allow Wikis or shared documents be created, as technical help may be required to build a formally correct ontology. The creation of an upper ontology for Benefits Management should provide a template in the form of a complete or semi-complete Terminology Box (T$\mathrm{BOX}$ ) for stakeholders to use.

Sebastian et al. [26] describe an approach to collaborative ontology development using workflows. The researchers highlight the need to define formal workflows for nonontology experts such as domain experts in the areas of medicine and gene research. This could be extended to business analysts or those working in the area of Benefits Management. The paper outlines a series of tasks that form a workflow for ontology generation, supported by an ontology that describes the process for creating an ontology. This allows those who are unfamiliar with the process of ontology generation to create an ontology from scratch using a collaborative method.

The importance of the change process in ontologies is the subject of the paper by Wang et al. [27]. In large scale ontology projects the ability to use and review a change process is part of the ontology building process. Ontology tools such as Protégé [28] and WebProtégé [3] include a change log. The change process is a key factor when a number of collaborators are working on a shared ontology.
The ontology engineering process is examined in Strohmaier et al. [29]. The researchers describe four aspects of ontology development dynamic, social, lexical and behavioral.

The dynamic aspects describe how ontologies change over time. The researchers found that changes occurred in bursts around the project start-up date and, during meetings between collaborators. The social aspects of ontology development see collaborators working in small groups of two or three people. The vocabulary of the ontology will stabilise as it becomes mature. This is described as the lexical aspect of the ontology development process and can be measured using a number of mathematical measures of texts such as word similarity or Vector Space Models (VSM) of corpora [30]. The behavioral aspects of ontology development describe how collaborators change the ontology over time. It was found that a change hierarchy saw developers modifying a high level concept and then going on to transform lower level concepts.

Tudorache [3] proposes the usage of WebProtégé as a collaborative ontology editing tool. The tool is light weight in comparison to desktop computer based tools, such as the existing Protégé [28] tool. The WebProtégé tool allows information to be entered via structured input forms which should be familiar to non-technical users, such as domain specialists. The forms can be tailored to a number of user groups. There is support for collaborative working such as threaded discussions, change notifications and change statistics notice boards.

\section{Cloud Computing CASE Studies}

A number of case studies were developed from primary and secondary sources. The case studies deal with different aspects of cloud computing, as described in the table below.

TABLE I. ORGANISATIONS REVIEWED

\begin{tabular}{|l|l|l|}
\hline Organisation & Type & Description \\
\hline Organisation A [8] & Micro Start-up \\
Company & $\begin{array}{l}\text { Provides solutions to the } \\
\text { music promotion industry } \\
\text { using PaaS/ public clouds. }\end{array}$ \\
\hline Organisation B [8] & $\begin{array}{l}\text { Actuarial Services } \\
\text { Consultancy }\end{array}$ & $\begin{array}{l}\text { Supplier of economic } \\
\text { modelling reports using } \\
\text { IaaS/PaaS on } \\
\text { public/private clouds. }\end{array}$ \\
\hline Organisation C [8] & $\begin{array}{l}\text { Public Sector Division } \\
\text { of Large Software } \\
\text { Company }\end{array}$ & $\begin{array}{l}\text { IaaS and SaaS solutions } \\
\text { via private clouds }\end{array}$ \\
\hline Organisation D [8] & $\begin{array}{l}\text { Public Sector } \\
\text { Managed Services } \\
\text { organisation }\end{array}$ & $\begin{array}{l}\text { Shared service between } \\
\text { two local authorities using } \\
\text { IaaS/SaaS. }\end{array}$ \\
\hline $\begin{array}{l}\text { Organisation E (new } \\
\text { primary research) }\end{array}$ & A large local authority & $\begin{array}{l}\text { Adoption of IaaS in a large } \\
\text { local authority with a } \\
\text { commercial partner. }\end{array}$ \\
\hline Organisation F [9] & $\begin{array}{l}\text { Oil and gas company } \\
\text { migration to IaaS }\end{array}$ & $\begin{array}{l}\text { Migration from an in house } \\
\text { data centre. }\end{array}$ \\
\hline Organisation G [10] & Media Group & $\begin{array}{l}\text { Software as a service for } \\
\text { distributed media workers. }\end{array}$ \\
\hline Organisation H [11] & $\begin{array}{l}\text { Quality of service for } \\
\text { three cloud services }\end{array}$ & $\begin{array}{l}\text { Study of factors effecting } \\
\text { ranking of quality of } \\
\text { service in IaaS. }\end{array}$ \\
\hline Organisation I [12] & $\begin{array}{l}\text { University's adoption } \\
\text { of cloud technology }\end{array}$ & $\begin{array}{l}\text { Cloud adoption in an } \\
\text { educational context }\end{array}$ \\
\hline
\end{tabular}




\begin{tabular}{|l|l|l|}
\hline Organisation J [13] & $\begin{array}{l}\text { Security benefits in } \\
\text { cloud computing }\end{array}$ & $\begin{array}{l}\text { Identification of security } \\
\text { benefits in cloud } \\
\text { computing. }\end{array}$ \\
\hline Organisation K [14] & $\begin{array}{l}\text { Implementation of } \\
\text { cloud computing by } \\
\text { doctors in South } \\
\text { Africa }\end{array}$ & $\begin{array}{l}\text { The benefits of using cloud } \\
\text { computing to enable } \\
\text { benefits such as better } \\
\text { communication. }\end{array}$ \\
\hline
\end{tabular}

The methodology used in this paper was to extract Benefits Management information from each case study which was then used to build an upper ontology for Benefits Management. The table below shows the IS/IT enablers for each case study.

\section{TABLE II. ENABLERS CROSS-REFERENCED TO CASE STUDIES}

\begin{tabular}{|c|c|}
\hline Enabler & Case Study \\
\hline Cost & A-K \\
\hline $\begin{array}{l}\text { Ease of movement from test } \\
\text { to production }\end{array}$ & A, B \\
\hline $\begin{array}{l}\text { Large scale storage with low } \\
\text { cost of ownership }\end{array}$ & $\mathrm{A}, \mathrm{B}, \mathrm{G}$ \\
\hline Shared development space & $\mathrm{A}, \mathrm{B}$ \\
\hline New products & $\mathrm{A}, \mathrm{B}, \mathrm{E}$ \\
\hline Flexibility of resources & $\mathrm{A}, \mathrm{B}, \mathrm{C}, \mathrm{H}, \mathrm{I}$ \\
\hline $\begin{array}{l}\text { Marketing power of cloud } \\
\text { computing }\end{array}$ & $\mathrm{B}, \mathrm{C}$ \\
\hline $\begin{array}{l}\text { New markets and } \\
\text { procurement models }\end{array}$ & $\mathrm{C}, \mathrm{D}, \mathrm{E}$ \\
\hline $\begin{array}{l}\text { Provide services to } 3^{\text {rd }} \\
\text { parties }\end{array}$ & $\mathrm{C}, \mathrm{D}, \mathrm{E}$ \\
\hline $\begin{array}{l}\text { Create infrastructure for } \\
\text { start-up companies }\end{array}$ & $\mathrm{E}$ \\
\hline Disaster recovery & $\mathrm{E}$ \\
\hline $\begin{array}{l}\text { Device independence and } \\
\text { geographical distribution }\end{array}$ & G, I, K \\
\hline $\begin{array}{l}\text { Improve employee } \\
\text { satisfaction }\end{array}$ & $\mathrm{F}, \mathrm{H}$ \\
\hline Improved security & $\mathrm{E}, \mathrm{J}$ \\
\hline
\end{tabular}

The table above shows that many of the enablers were present in the organisations covered by the case studies. The enablers can be split into two groups, business and operational.

Cost was an enabler in all organisations. The usage of IaaS was seen as enabler to reduce costs in the short-term and a major reason for the uptake of cloud computing. Repeated cost reduction may not be feasible in the long-term and other enablers should be examined.

There are a number of new products being created by cloud computing such as storage solutions, data science applications and development environments. These enable organisations to gain new customers and to enter new markets.

Marketing cloud service enablers allow organisations to attract new customers and to maintain existing customers who may move to cloud based solutions in the future.

Lower costs of market entry are afforded by cloud computing which utilises rental of resources. Organisations can enter new markets without capital expenditure and maintenance costs. Organisations with existing infrastructure or those who require high levels of fixed resources can sell excess capacity.

The freeing up of staff from repetitive and tedious infrastructure development and maintenance is one of the main benefits. The dis-benefit of redundancies from outsourcing to the cloud is acknowledged. Organisations D \& $\mathrm{E}$ in the case studies are large local authorities which have successfully adopted cloud infrastructure and redeployed staff into new customer facing roles.

Public authorities, academic institutions and non-profit organisations can use cloud infrastructure to allow start-up organisations to develop. Organisation $\mathrm{E}$ has used this approach to generate economic development The BDN for business enablers is shown below.

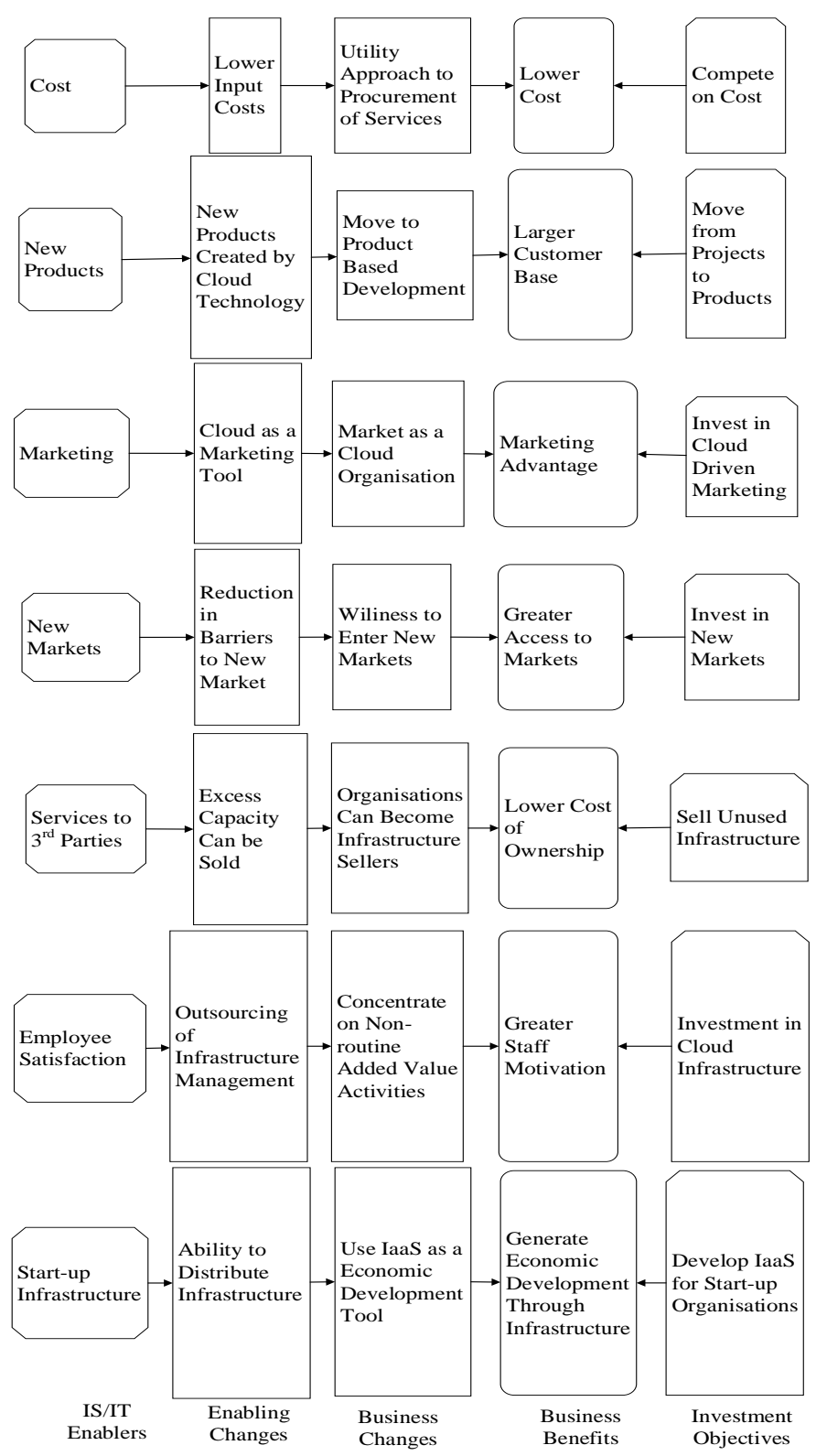

Fig. 2. for Business Enablers 
The operational enablers are now described. The largescale storage offered by cloud computing is a major operational enabler [31]. The backup, replication and disaster recovery of large amounts of data can be outsourced at a very low cost. Many organisations described in the case studies have large amounts of critical business data which is being moved into the cloud [32]. When low cost storage is combined with fast Internet connections an enabling cloud technology is created.

Resource procurement of hardware and software was previously a capital investment decision, requiring long-term planning, without the ability to adjust resources quickly as business needs change. The advent of cloud computing has seen the ability to purchase resources on-demand, through spot instances as well as through fixed resources to cope with base demand.

New approaches to the development of software solutions have been established using hybrid and public cloud technology. Organisation A has established a joint development environment with customers with a public cloud based platform. This has produced an operational approach that is more intimate with the customer and reduces operational risk though shared developments and cost.

Public and hybrid clouds enable organisations to create and store virtual machines at a low cost. Separate physical hardware and software is no longer required. Virtual machines can be moved from test to development more easily.

The provision of disaster recovery is an emerging market for cloud computing providers. Organisations will effectively outsource their disaster recovery operations to the cloud provider. This is advantageous because cloud storage is replicated and backed up multiple times across a number of geographical locations [33]. Virtual machines can be made ready to provide instant services if a company's own data centre is unavailable. Expertise can be concentrated at cloud providers that would be difficult to replicate outside large IS/IT providers.

Services can be accessed from a number of devices such as phone apps, tablets and desktop machines more easily using cloud based services [19]. The operational requirement to install and manage software and data falls on the cloud provider.

The high availability of data and secure access can be managed by the cloud provider. Systems and expertise will be more advanced than that afforded by small in-house providers. However, there are problems with outsourcing security due to loss of control of the organisation and conflict of interests if the cloud provider provides services to competitors.

The operational enablers for cloud computing are shown in the figure below.

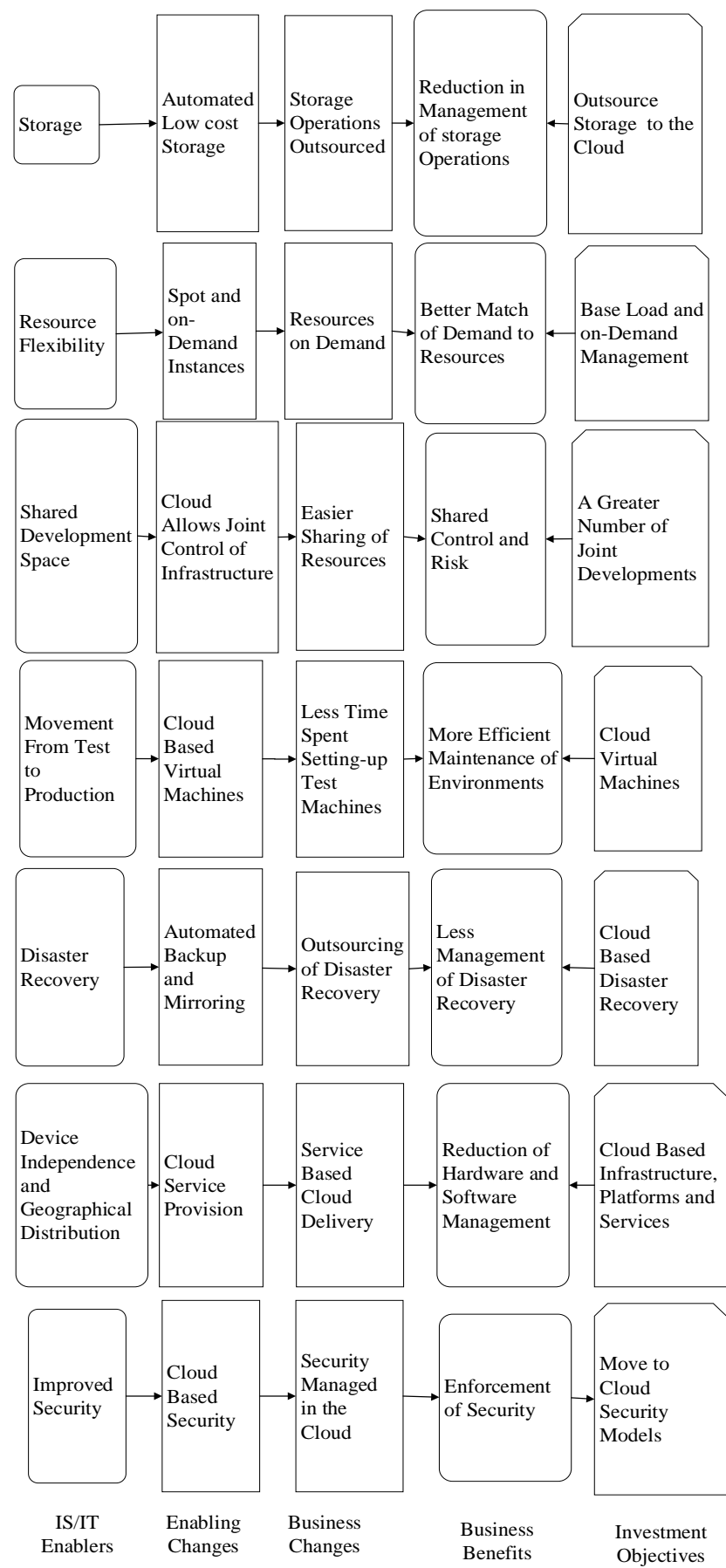

Fig. 3. Operational Enablers

The benefits are classified in the table below. The financial benefits are centered on the lower cost of ownership from using utility infrastructure. New markets (such as government provision platforms) could be entered which would provide financial benefits. 
Operational efficiencies provide further financial benefits such as the ability to create new environments and to outsource the management of computing resources. Reduced fixed costs will result from the move to a 'rental' model as opposed to spending money on internal IS/IT infrastructure.

Quantifiable benefits include improvements in service quality, with the ability of users to vary the amount of resources they use. The speed of functionality delivery and the availability of resources were improved. There may be internal staff reductions due to cloud computing infrastructure investments. The operational benefits of the cloud based IS/IT such as the lowering of e-mail traffic and increased security in the cloud are measureable. Future benefits from new technologies seen in PaaS and enabling data science innovations can be measured using forecasting techniques.

The marketing benefits of cloud computing are important to many of the organisations. These benefits are difficult to measure in the short-term but are observable in internal and external marketing positions in the organisations.

TABLE III. ClassifICATION OF BENEFITS

\begin{tabular}{|c|c|c|c|}
\hline $\begin{array}{l}\text { Degree of } \\
\text { Explicitness }\end{array}$ & Do New Things & Do Things Better & $\begin{array}{l}\text { Stop Doing } \\
\text { Things }\end{array}$ \\
\hline Financial & $\begin{array}{l}\text { Lower cost of } \\
\text { ownership } \\
\text { Reduced fixed } \\
\text { costs. }\end{array}$ & $\begin{array}{l}\text { Reducing time to } \\
\text { create infrastructure }\end{array}$ & $\begin{array}{l}\text { Managing own } \\
\text { infrastructure. } \\
\text { Grid computing }\end{array}$ \\
\hline $\begin{array}{l}\text { Quantifiabl } \\
\mathrm{e}\end{array}$ & $\begin{array}{l}\text { Improved quality } \\
\text { of service } \\
\text { Customer self } \\
\text { service }\end{array}$ & $\begin{array}{l}\text { Faster turnaround of } \\
\text { new functionality } \\
\text { Speed of delivery } \\
\text { Availability } \\
\text { improvements }\end{array}$ & $\begin{array}{l}\text { Internal } \\
\text { infrastructure } \\
\text { Direct } \\
\text { employment of } \\
\text { staff through } \\
\text { infrastructure } \\
\text { outsourcing }\end{array}$ \\
\hline Measurable & $\begin{array}{l}\text { Lower e-mail } \\
\text { traffic } \\
\text { New markets for } \\
\text { Big Data and Data } \\
\text { Science }\end{array}$ & $\begin{array}{l}\text { PaaS innovations } \\
\text { Security of data. } \\
\text { Improve customer } \\
\text { satisfaction }\end{array}$ & $\begin{array}{l}\text { E-mail traffic } \\
\text { Storing } \\
\text { information on } \\
\text { individual } \\
\text { computers }\end{array}$ \\
\hline Observable & $\begin{array}{l}\text { Better customer } \\
\text { intimacy. } \\
\text { Improved } \\
\text { marketing } \\
\text { Move from project } \\
\text { to product based } \\
\text { solutions } \\
\text { Sell infrastructure } \\
\text { and services } \\
\text { outside the } \\
\text { organisation }\end{array}$ & $\begin{array}{l}\text { Actively market to } \\
\text { customers }\end{array}$ & $\begin{array}{l}\text { Waiting for } \\
\text { customers to } \\
\text { 'come to the } \\
\text { organisation' }\end{array}$ \\
\hline
\end{tabular}

The cloud investment portfolio is shown below. The portfolio shows long-term strategic investments for organisations adopting cloud technologies such as infrastructure, services and storage.
Private clouds are being developed and there is some development of hybrid technologies which utilise combinations of private and public cloud ownership.

High potential investments are riskier investments that may yield higher returns. Small innovative organisations may use PaaS to deliver unique products that will differentiate them from the mass market. Data science investments enabled by cloud computing promise high growth, but may be high risk due to the immaturity of the technology in this area.

Key operational investments will be supported in the shortto medium-term. Private clouds will be developed by organisations at high cost to organisations, based on in-house servers or on customers' hardware. Non-cloud and grid computing solutions will be supported in the short-term but will be replaced by cloud technologies due to cost and usability issues. Public clouds will be important in the shortterm for many organisations; however, their ubiquity and low cost will not generate competitive advantage in the long-term.

TABLE IV. Cloud InVEstment PortFolio

\begin{tabular}{|c|c|}
\hline Strategic & High Potential \\
\hline $\begin{array}{l}\text { IaaS } \\
\text { SaaS } \\
\text { Cloud storage } \\
\text { Private/hybrid clouds }\end{array}$ & $\begin{array}{l}\text { PaaS } \\
\text { Marketing of Cloud Computing } \\
\text { Market places such as G-Cloud } \\
\text { Big Data \& Data Science } \\
\text { Shared Services }\end{array}$ \\
\hline $\begin{array}{l}\text { Existing customers with their } \\
\text { own hardware } \\
\text { Clustered in-house servers with } \\
\text { cloud extensions } \\
\text { Private Cloud }\end{array}$ & $\begin{array}{l}\text { Non-cloud Based Software } \\
\text { Grid Computing } \\
\text { Public Cloud (long-term) }\end{array}$ \\
\hline Key Operation & Support \\
\hline
\end{tabular}

\section{AN ONTOLOGY FOR BENEFITS MANAGEMENT IN CLOUD COMPUTING}

An ontology was generated from case studies previously described. This provides a formal description of the Benefits Management terminology, relationships and assertions provided by the case studies.

The ontology was created so that the terminology can be reused across a number of projects. The terminology for the Benefits Management ontology has been uploaded to the WebProtégé website [34]. This allows the full ontology to be viewed, critiqued and used by other researchers. The assertions for the case studies described in this paper are held in a separate ontology file that can be supplied or uploaded on request. Also, the assertions can be overlaid on the terminology to provide a full ontology. The decision to separate the terminology and assertions was to allow for the reuse of the terminology.

\section{A. Ontology Classes}




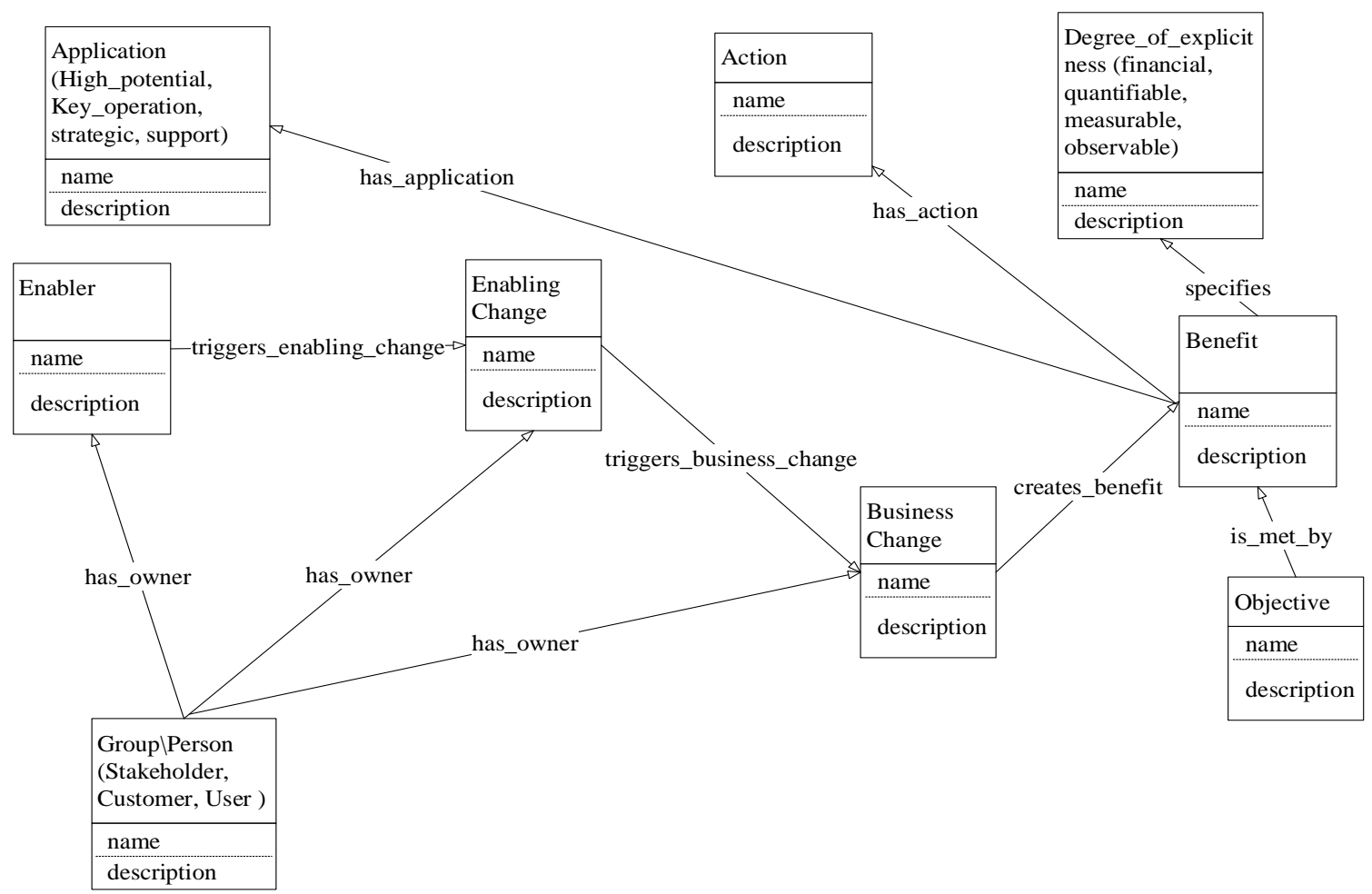

Fig. 4. Overview of Main Ontology Classes

The figure above shows the main ontology classes (entities). A full description can be found in the WebProtégé project [34]. The Benefits Dependency Network forms the core of the ontology with semantic linkages between enablers, changes and benefits. Each entity can be related to the owner such as a group or stakeholder. Benefits can be linked to objectives and be classified or related to investment portfolio applications.

The names entities shown in parenthesis are child entities. An expanded example for 'Degree_of_explicitness' is shown below.

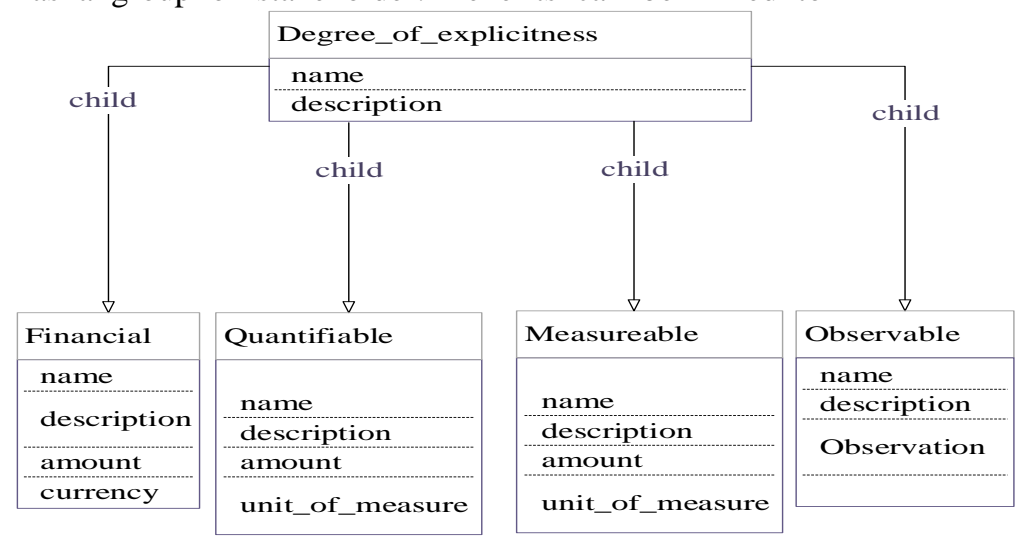

Fig. 5. Degree of Explicitness

\section{B. Ontology Implementation}

An example of the ontology class implementation (assertions) is shown below. The cost enabler sees lower input costs in the business. The organisation purchases on price.
Cloud computing resources are treated as utilities which can be supplied by a large number of suppliers. This gives the benefit of lower cost to the business which, meets the business objective of competing on cost. This is a new strategic investment which can be expressed financially. 


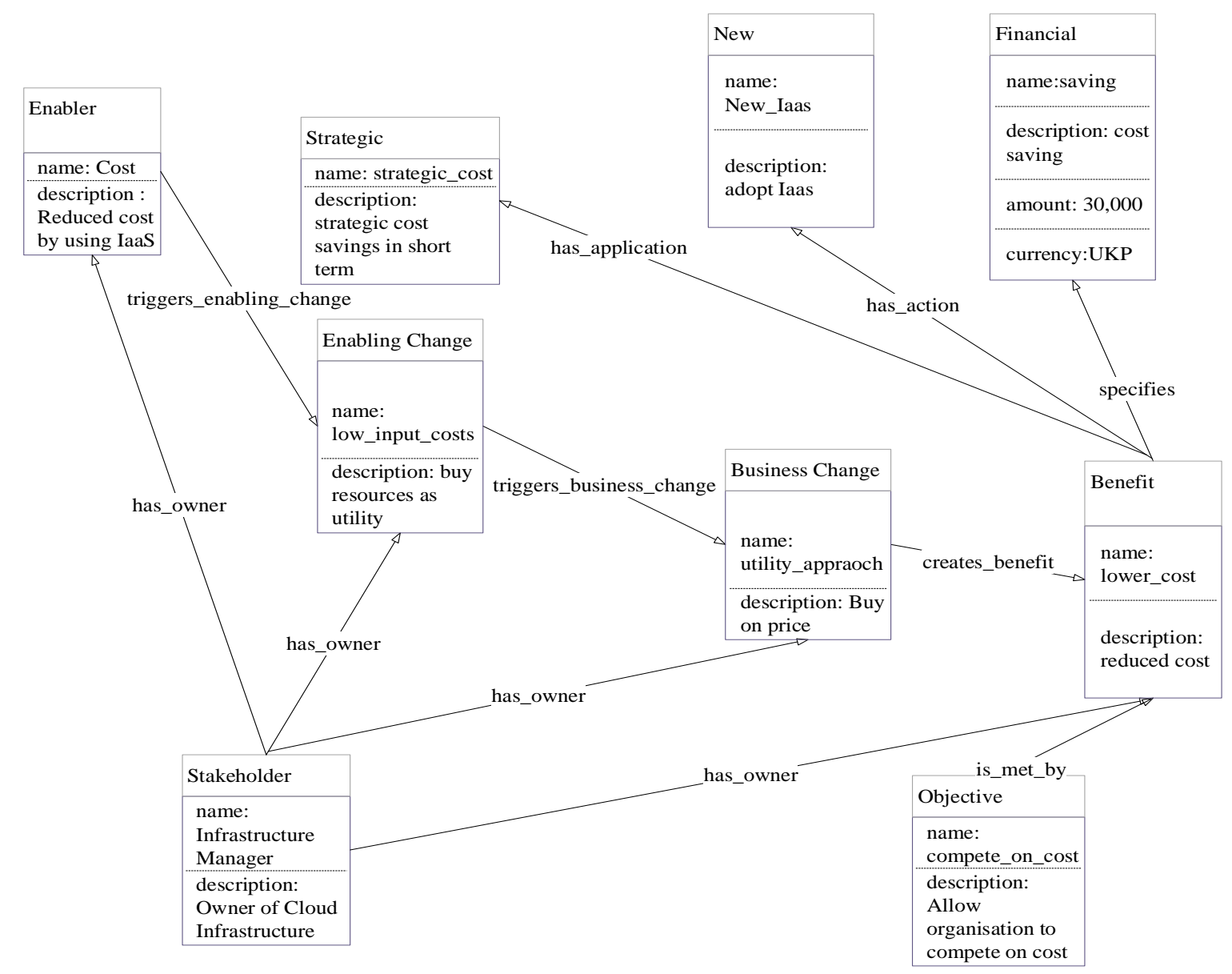

Fig. 6. Ontology Implementation

\section{SPARQL Queries}

SPARQL [21] can be used to provide Benefits Management outputs from the ontology. The namespace prefix 'bm' signifies 'benefits management'. SPARQL traverses the semantic data held in the ontology to produce outputs.

Three examples of useful outputs from the Benefits Management approach identified in the literature which are represented as SPARQL queries are shown in the table below.
The 'Benefits Stream' query traverses the Benefits Dependency Network (BDN) to describe the linkage between enablers, change, benefits and objectives. The 'Stakeholder Analysis' query examines the relationships between benefits and their owners and the stakeholders' commitment to the benefits. The 'Dimensions of Competence' query examines the relationship between drivers in the business such as the need to reduce costs in the business and the ability to meet the drivers from competences within the business. 
TABLE V. SPARQL QUERIES FOR BENEFITS MANAGEMENT REPORTS

\begin{tabular}{|c|c|}
\hline Description & SPARQL Query \\
\hline $\begin{array}{l}\text { Benefits Stream [1] p. } 102- \\
\text { A set of related benefits and } \\
\text { their associated business and } \\
\text { enabling changes and } \\
\text { enabling IS/IT }\end{array}$ & 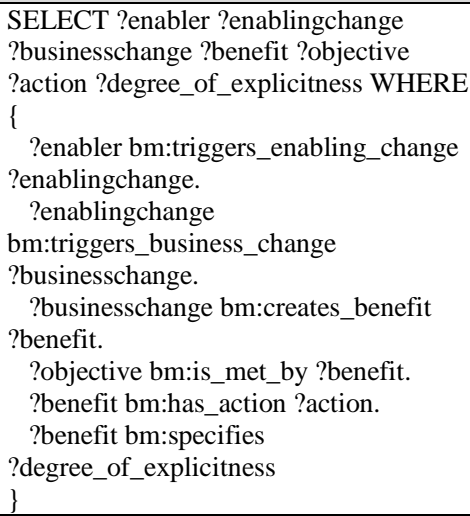 \\
\hline $\begin{array}{l}\text { Stakeholder analysis [1] p. } \\
179 \text { - Stakeholder groups, } \\
\text { their benefits, changes and } \\
\text { commitments to change }\end{array}$ & $\begin{array}{l}\text { SELECT ?owner ?benefit ?change } \\
\text { ?commitment ?commitment_action } \\
\text { WHERE } \\
\text { \{ } \\
\text { ?benefit bm:has_owner ?owner. } \\
\text { ?benefit bm:needs_change ?change. } \\
\text { ?change bm:has_commitment } \\
\text { ?commitment. } \\
\text { ?commitment } \\
\text { bm:has_commitment_action } \\
\text { ?commitment_action } \\
\text { \} }\end{array}$ \\
\hline $\begin{array}{l}\text { Dimensions of competence } \\
\text { [1] p. } 114-\text { The different } \\
\text { capabilities of the } \\
\text { organisation (this will get } \\
\text { competency type and } \\
\text { description of competency) }\end{array}$ & 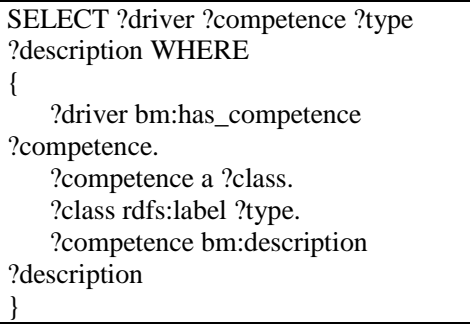 \\
\hline
\end{tabular}

\section{CONCLUSIONS}

This paper has described the development of an ontology for Benefits Management in cloud computing. This has delivered two unique contributions. Firstly, the Benefits Management approach has been enhanced to include semantic constructs and a formal knowledge description. This is enhanced using by WebProtégé, which allows collaborative development.

Secondly, an ontology has been developed and populated with case studies that can be used as a 'service' for those interested in Benefits Management for cloud computing.

\section{A. Advantages of Ontology for Benefits Management}

There are a number of advantages in developing an ontology for Benefits Management in cloud computing. The usage of semantic modelling techniques improves the expressive quality of the tools found within Benefits Management. An example could be the Benefits Dependency Network (BDN) which has linkages between enablers, change and benefits that are more expressive than using a simple network pattern.

Description logics allow reasoning to take place across the ontology. This has been demonstrated using the SPARQL language. An example can be seen in the BDN where "Cloud Computing Enablers that create change for financial benefits for strategic investments" can be found. The reasoning mechanism is more powerful and flexible than that found in technologies such as relation databases and, the terminology, relationships and assertions can be changed in light of new knowledge. Knowledge can be 'created' by concepts such as multiple-inheritance of knowledge derived through reasoning.

The use of collaborative ontology tools such as WebProtégé is ideally suited to Benefits Management development. Stakeholders collaborate to define and edit terminology and assertions. The collaborative tools provide change notification and auditing required in a multistakeholder environment.

\section{B. Importance of Benefits Management for Cloud Computing}

There has been heavy investment in cloud computing, which is set to increase over the next decade. It is important to consider the benefits cloud computing will bring to organisations. This paper has laid the foundations for considering what the likely benefits are and has structured them into an appropriate knowledge representation.

\section{FUTURE WORK}

\section{A. Expansion of Web Protégé Ontology}

The terminology of the Benefits Management ontology can be improved by an internal review by the authors and a peer review of the WebProtégé project, which is designed to provide a collaborative approach to ontology development.

A number of case studies have been analysed, however, further work is underway to add additional assertions to the ontology through the analysis of further case studies.

\section{B. Usage of Ontology by Organisations}

WebProtégé is designed for domain experts and nontechnical knowledge engineers. Further work will involve the definition of input forms for the entry benefits information. A number of client interfaces are being developed to provide rich user interfaces for non-expert users for the T-BOX.

The T-BOX for the ontology described in this paper can be downloaded from WebProtégé [34] and the R-BOX and A$\mathrm{BOX}$ are available on request. Organisations can use the TBOX to develop their own benefits managements ontology (by defining an R-BOX and A-BOX) using WebProtégé or a user interface (which are under development).

Toolsets to allow easier Benefits Management ontology creation are required. Matching is a key approach which can be used to match enablers, to changes and the benefits generated from stakeholder groups. Mao et al. [35] describe a mapping approach based on Vector Space Models (VSM), that allow textual descriptions of ontology elements to be mapped.

\section{REFERENCES}

[1] J. Ward and E. Daniel, Benefits Management: How to Increase the Business Value of Your IT Projects. Wiley, 2012.

[2] J. Peppard, J. Ward, and E. Daniel, "Managing the realization of business benefits from IT investments," MIS Quarterly Executive, vol. 6, no. 1, pp. 1-11, 2007. 
[3] T. Tudorache, C. Nyulas, N. F. Noy, and M. A. Musen, "WebProtégé: A collaborative ontology editor and knowledge acquisition tool for the web," Semantic web, vol. 4, no. 1, pp. 89-99, 2013.

[4] P. Mell and T. Grance, "The NIST definition of cloud computing," 2011.

[5] D. Agrawal, "Towards the End-to-End Design for Big Data Management in the Cloud: Why, How, and When?," presented at the BTW, 2013, pp. 15-16.

[6] I. T. Foster and R. K. Madduri, "Science as a service: how on-demand computing can accelerate discovery," presented at the Proceedings of the 4th ACM workshop on Scientific cloud computing, 2013, pp. 1-2.

[7] C. Wang, K. Ren, W. Lou, and J. Li, "Toward publicly auditable secure cloud data storage services," Network, IEEE, vol. 24, no. 4, pp. 19-24, 2010.

[8] R. Greenwell, X. Liu, and K. Chalmers, "Benefits Management of Cloud Computing Investments," International Journal of Advanced Computer Science and Applications (IJACSA), vol. 5, no. 7, 2014

[9] A. Khajeh-Hosseini, D. Greenwood, and I. Sommerville, "Cloud migration: A case study of migrating an enterprise it system to iaas," presented at the Cloud Computing (CLOUD), 2010 IEEE 3rd International Conference on, 2010, pp. 450-457.

[10] N. Convery and K. Ferguson-Boucher, "Storing information in the cloud," Bulletin of Information and Records Management Society, Issue, pp. 3-5, 2010.

[11] S. K. Garg, S. Versteeg, and R. Buyya, "A framework for ranking of cloud computing services," Future Generation Computer Systems, vol. 29, no. 4, pp. 1012-1023, 2013

[12] V. Chang and G. Wills, "A University of Greenwich Case Study of Cloud Computing," E-Logistics and E-Supply Chain Management: Applications for Evolving Business, p. 232, 2013.

[13] M. Shi, "Capturing strategic competences: cloud security as a case study," Journal of Business Strategy, vol. 34, no. 3, pp. 41-48, 2013.

[14] A. Coleman, M. E. Herselman, and M. Coleman, "Improving Computermediated Synchronous Communication of Doctors in Rural Communities through Cloud Computing A Case study of Rural Hospitals in South Africa.," Oriental Anthropologists, vol. 13, no. 1, 2013.

[15] C. Perera, A. Zaslavsky, P. Christen, and D. Georgakopoulos, "Sensing as a service model for smart cities supported by internet of things," Transactions on Emerging Telecommunications Technologies, vol. 25, no. 1, pp. 81-93, 2014.

[16] G-Cloud, "G-Cloud - Home of the UK Government G-Cloud Programme G-Cloud," 2013. [Online]. Available: http://gcloud.civilservice.gov.uk/. [Accessed: 24-Nov-2014].

[17] J. Bughin, M. Chui, and J. Manyika, "Clouds, big data, and smart assets: Ten tech-enabled business trends to watch," McKinsey Quarterly, vol. $56,2010$.

[18] O. H. Alhazmi and Y. K. Malaiya, "Evaluating disaster recovery plans using the cloud," presented at the Reliability and Maintainability Symposium (RAMS), 2013 Proceedings-Annual, 2013, pp. 1-6.

[19] H. T. Dinh, C. Lee, D. Niyato, and P. Wang, "A survey of mobile cloud computing: architecture, applications, and approaches," Wireless communications and mobile computing, vol. 13, no. 18, pp. 1587-1611, 2013.
[20] D. S. Marcon, R. R. Oliveira, M. C. Neves, L. S. Buriol, L. P. Gaspary, and M. P. Barcellos, "Trust-based Grouping for Cloud Datacenters: improving security in shared infrastructures," presented at the IFIP Networking Conference, 2013, 2013, pp. 1-9.

[21] O. Hartig, "SPARQL for a web of linked data: semantics and computability," in The Semantic Web: Research and Applications, Springer, 2012, pp. 8-23.

[22] D. Allemang and J. Hendler, Semantic Web for the Working Ontologist: Effective Modeling in RDFS and OWL. Elsevier Science, 2011.

[23] M. Hepp, "Goodrelations: An ontology for describing products and services offers on the web," in Knowledge Engineering: Practice and Patterns, Springer, 2008, pp. 329-346.

[24] H. Rijgersberg, M. van Assem, and J. Top, "Ontology of units of measure and related concepts," Semantic Web, vol. 4, no. 1, pp. 3-13, 2013.

[25] S. Walk, P. Singer, M. Strohmaier, D. Helic, N. Noy, and M. Musen, "Sequential Usage Patterns in Collaborative Ontology-Engineering Projects," arXiv preprint arXiv: 1403.1070, 2014.

[26] A. Sebastian, N. F. Noy, T. Tudorache, and M. A. Musen, "A Generic Ontology for Collaborative Ontology-Development Workflows," in Proceedings of the 16th international conference on Knowledge Engineering: Practice and Patterns, Berlin, Heidelberg, 2008, pp. 318328

[27] H. Wang, T. Tudorache, D. Dou, N. F. Noy, and M. A. Musen, "Analysis of User Editing Patterns in Ontology Development Projects," presented at the On the Move to Meaningful Internet Systems: OTM 2013 Conferences, 2013, pp. 470-487.

[28] Protege, "The Protégé Ontology Editor and Knowledge Acquisition System," 2014. [Online]. Available: http://protege.stanford.edu/. [Accessed: 24-Nov-2014].

[29] M. Strohmaier, S. Walk, J. Pöschko, D. Lamprecht, T. Tudorache, C. Nyulas, M. A. Musen, and N. F. Noy, "How ontologies are made: Studying the hidden social dynamics behind collaborative ontology engineering projects," Web Semantics: Science, Services and Agents on the World Wide Web, vol. 20, pp. 18-34, 2013.

[30] C. Manning, P. Raghavan, and Schutze, Introduction to Information Retrieval. Cambridge University Press, 2008.

[31] A. N. Toosi, R. N. Calheiros, and R. Buyya, "Interconnected Cloud Computing Environments: Challenges, Taxonomy, and Survey," ACM Computing Surveys (CSUR), vol. 47, no. 1, p. 7, 2014.

[32] Y. Han, "On the clouds: a new way of computing," Information Technology and Libraries, vol. 29, no. 2, pp. 87-92, 2013.

[33] Z. Wu, M. Butkiewicz, D. Perkins, E. Katz-Bassett, and H. V. Madhyastha, "Spanstore: Cost-effective geo-replicated storage spanning multiple cloud services," presented at the Proceedings of the TwentyFourth ACM Symposium on Operating Systems Principles, 2013, pp. 292-308.

[34] R. Greenwell, "Benefits Management Web-protege project," 2014. [Online]. Available: http://webprotege.stanford.edu/\#Edit:projectId=d9a84e6c-9448-4921b38c-e5e4f0e0ef2c.

[35] M. Mao, Y. Peng, and M. Spring, "An adaptive ontology mapping approach with neural network based constraint satisfaction," Web Semantics: Science, Services and Agents on the World Wide Web, vol. 8, no. 1 , pp. $14-25,2010$ 